\title{
MONTAGEM E ACURÁCIA DE UM SISTEMA EXPERIMENTAL DE PESAGEM PARA CALIBRAÇÃO DE SENSORES DE UMIDADE DO SOLO ${ }^{1}$
}

\author{
Assembling and accuracy of an experimental weighing system for \\ calibration of soil moisture sensors
}

\author{
Ricardo Martins Santos², Aureo Silva de Oliveira ${ }^{3}$, Lucas Melo Vellame ${ }^{4}$, Flávia Janaína Carvalho Brandão ${ }^{5}$
}

\begin{abstract}
RESUMO
O presente trabalho descreve os procedimentos de desenvolvimento e teste de um sistema de pesagem de grande capacidade para utilização em gravimetria como método padrão de calibração de sensores de umidade do solo. O trabalho foi desenvolvido no Laboratório de Irrigação e Drenagem, Centro de Ciências Agrárias e Ambientais da Universidade Federal da Bahia, campus de Cruz das Almas (12 $\left.40^{\circ} \mathrm{S}, 39^{\circ} 30^{\prime} \mathrm{W}\right)$, BA. O princípio de funcionamento do sistema de pesagem baseia-se no seu componente principal, a célula de carga. Utilizou-se uma célula de carga do tipo flexão, de capacidade $60 \mathrm{~kg}$ e sensibilidade de $2 \mathrm{mV} / \mathrm{V}$, quando submetida à carga máxima. A calibração foi realizada por meio de massas-padrão de 1,5,10 e $20 \mathrm{~kg}$ em sete ciclos de carregamento e descarregamento. O modelo de calibração encontrado foi do tipo linear $\left(\mathrm{r}^{2}=0,999\right)$ e os erros de repetibilidade, histerese e linearidade foram da ordem de $0,119,0,068$ e $0,009 \%$ do final de escala (FE), respectivamente. Os limites do erro de acurácia, que representa o desempenho geral do sistema, foram $\pm 0,083 \%$ de FE. O sistema de pesagem foi considerado adequado, do ponto de vista de funcionalidade e desempenho, para calibração em condições controladas, de sensores de umidade do tipo sonda de capacitância, utilizando-se amostras indeformadas de solo. O custo final do sistema foi estimado em R \$ 1.800,00 (US\$ 766,00).
\end{abstract}

Termos para indexação: Gravimetria, célula de carga, instrumentação agrícola.

\begin{abstract}
This work describes the development and testing of a large-capacity weighing system for calibration of soil moisture sensors in which the gravimetric method is taken as the standard one. The experiment was conducted at the Laboratório de Irrigação e Drenagem, Centro de Ciências Agrárias e Ambientais da Universidade Federal da Bahia, town of Cruz das Almas (1240’S, 39³0’W), State of Bahia, Brazil. The main component of the system was a $60-\mathrm{kg}$ load cell with a $2-\mathrm{mV} / \mathrm{V}$ sensibility when submitted to the maximum load. In the calibration process standard weights of 1,5,10 and $20 \mathrm{~kg}$ were used during seven loading and unloading cycles. A linear calibration model $\left(\mathrm{r}^{2}=0.999\right)$ was found and the repeatability, hysteresis, and linearity errors were $0.119 \%, 0.068 \%$, and $0.009 \%$ of full scale (FS). The accuracy limits, which represent the overall performance of the weighing system, were $\pm 0.083 \%$ of FS. The weighing system, in terms of functionality and performance, were considered to be adequate for calibration of soil moisture sensors, like capacitance probes, with undisturbed soil samples under laboratory conditions. The estimated final cost of the system was US\$ 766.00.
\end{abstract}

Index terms: Gravimetric method, load cell, agricultural instrumentation.

(Recebido para publicação em 2 de junho de 2005 e aprovado em 23 de fevereiro de 2006)

\section{INTRODUÇÃO}

No solo, o fenômeno de retenção da água (resultante de forças de retenção associadas à matriz do solo) contra forças externas (decorrentes, por exemplo, do campo gravitacional) tem sido há muito reconhecido como uma das funções primárias do solo na sustentação do crescimento e desenvolvimento das plantas sob condições de suprimento intermitente de água (GROENEVELT \& BOLT, 1971; LIBARDI, 2000). Do ponto de vista agrícola, a importância da umidade do solo estende-se também a outros campos como a mecanização, fertilização e irrigação da parcela cultivada.

Para determinação do teor de água no solo os métodos atualmente disponíveis podem ser genericamente classificados em diretos e indiretos. A gravimetria é considerada um método direto, em que a massa de água presente numa dada amostra de solo é obtida por diferença entre o peso da amostra antes e depois da secagem em estufa de circulação forçada de ar por um intervalo mínimo de $24 \mathrm{~h}$ sob temperatura de $105^{\circ} \mathrm{C}$. Os métodos indiretos geralmente empregam sensores que requerem algum tipo

\footnotetext{
${ }_{1}^{1}$ Parte da dissertação de mestrado do primeiro autor apresentada à Universidade Federal da Bahia/UFBA - Cruz das Almas, BA, para obtenção do título de Mestre em Ciências Agrárias.

2 Engenheiro Agrônomo, Companhia de Desenvolvimento dos Vales do São Francisco e Parnaíba/CODEVASF-Aracaju, SE.

${ }^{3}$ Engenheiro Agrônomo, Professor PhD, Núcleo de Engenharia de Água e Solo/NEAS - Universidade Federal da Bahia/UFBA - 44.380-000 Cruz das Alams, BA - aureo@ufba.br

${ }^{4}$ Engenheiro Agrônomo, Mestrando em Ciências Agrárias, Núcleo de Engenharia de Água e Solo/NEAS - Universidade Federal da Bahia/UFBA.

${ }^{5}$ Engenheira Agrônoma, MSc em Ciências Agrárias, Núcleo de Engenharia de Água e Solo/NEAS - Universidade Federal da Bahia/UFBA.
} 
de calibração. Nestes casos, a gravimetria é adotada como método padrão devido à sua simplicidade, praticidade e precisão, especialmente quando se usa balança digital com resolução próxima de centésimos de grama. Por outro lado, apresenta desvantagens por ser um método destrutivo e demorado, quando comparado aos métodos indiretos (GILBERTO JÚNIOR, 2003), dificultando a sua aplicação nos casos em que o conhecimento da umidade solo é exigido com maior freqüência.

A calibração e a avaliação do desempenho de sensores de umidade podem ser feitas no campo ou em laboratório. Neste último caso, amostras de solo, de preferência indeformadas, são extraídas do perfil do solo e submetidas a regimes de molhamento e secamento. $\mathrm{O}$ tamanho da amostra de solo para calibração do sensor depende do tipo e princípio de funcionamento do equipamento, bem como da precisão desejada. Sondas de nêutrons e alguns modelos de sondas de capacitância podem requerer amostras de grande massa, o que demanda sistemas de pesagem de maior capacidade. Nestes casos o custo de aquisição de balanças de precisão torna-se um sério fator limitante e o desenvolvimento de plataformas de pesagem a partir de componentes de baixo custo pode ser uma alternativa viável.

Objetivou-se com este estudo desenvolver um sistema de pesagem de amostras indeformadas de solo e avaliar os seus limites de confiabilidade, com ênfase nos erros de repetibilidade, histerese, linearidade e acurácia do sistema, para fins de calibração de sondas de capacitância.

\section{MATERIAL E MÉTODOS}

O trabalho foi desenvolvido no Laboratório de Irrigação e Drenagem, do Núcleo de Engenharia de Água e Solo, do Centro de Ciências Agrárias e Ambientais da Universidade Federal da Bahia, campus de Cruz das Almas $\left(12^{\circ} 40^{\prime} \mathrm{S}, 39^{\circ} 30^{\prime} \mathrm{W}\right)$, Bahia. Os seguintes materiais e equipamentos foram utilizados para confecção do sistema de pesagem: três chapas de aço nas dimensões de $40 \mathrm{~cm} \mathrm{x}$ $40 \mathrm{~cm} \times 0,5 \mathrm{~cm}$, três cantoneiras de $40 \mathrm{~cm} \times 10 \mathrm{~cm}$, quatro parafusos para fixação, uma célula de carga, massas-padrão de $1,5,10$ e $20 \mathrm{~kg}$ e um módulo indicador digital (modelo 8132, Toledo do Brasil S.A., São Paulo, SP) ${ }^{6}$ programado para uma resolução de $10 \mathrm{~g}$. Após montagem, o sistema de pesagem se apresentou como visto na Figura 1.

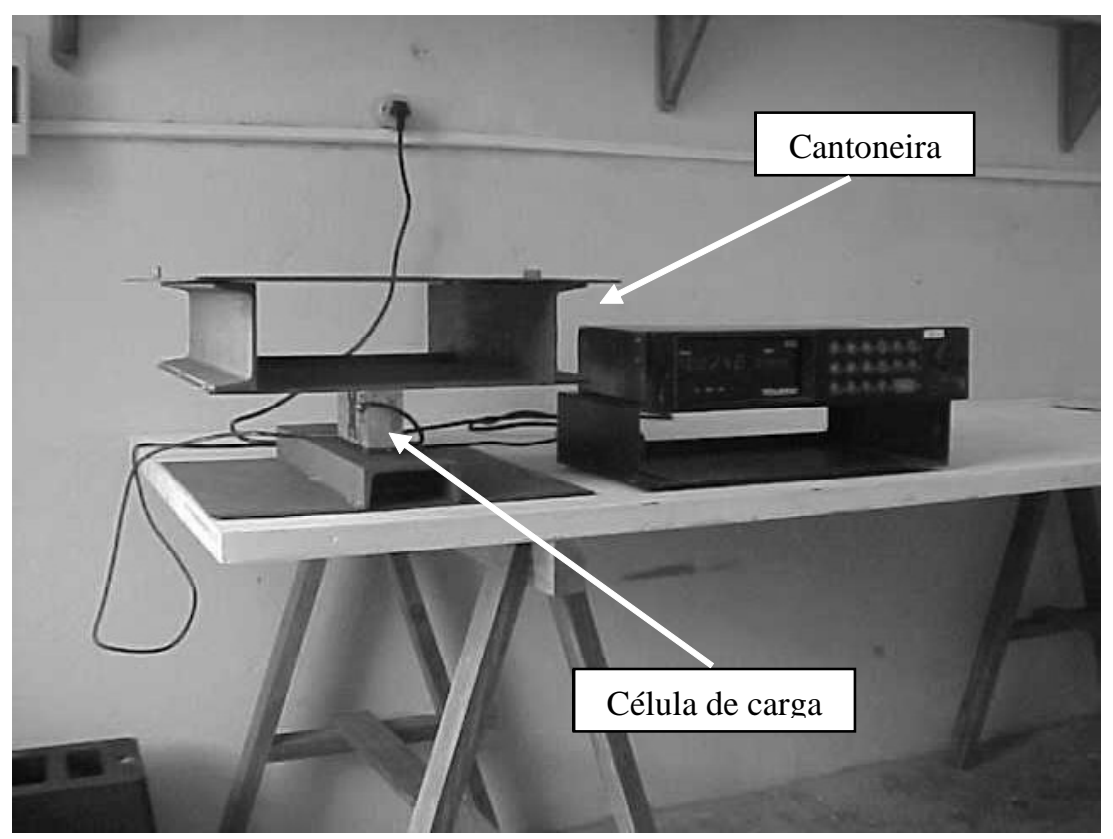

FIGURA 1 - Vista geral do sistema de pesagem (plataforma à esquerda e módulo indicador à direita), com indicação da célula de carga e uma das cantoneiras instaladas para evitar deformação.

\footnotetext{
${ }^{6}$ A menção de marcas registradas e modelos não implica em recomendação expressa por parte dos autores.
} 
O principal componente do sistema de pesagem é a célula de carga, que em função da tensão de alimentação emite um sinal elétrico proporcional à massa aplicada. A célula de carga utilizada neste trabalho (Figura 2) era do tipo flexão, com capacidade máxima de $60 \mathrm{~kg}$, possuindo compensação de temperatura e sensibilidade nominal de 2 $\mathrm{mV} / \mathrm{V}$ quando submetida a uma carga máxima de $60 \mathrm{~kg}$. Esta última característica define a sensibilidade do sensor, dada neste caso, pela variação do sinal de saída por unidade tensão de alimentação.

A célula de carga da Figura 2 é constituída de extensiômetros, que segundo Coelho Filho et al. (2004), compõem-se de uma folha plástica coberta com finas trilhas de um material condutor. Quando uma superfície à qual o extensiômetro está aderido se deforma, o comprimento e o diâmetro das trilhas se alteram, variando conseqüentemente a sua resistência elétrica em função da massa a que a célula é submetida.

As dimensões e capacidade da plataforma de pesagem devem ser definidas em função da massa de solo a ser medida e do tipo de sensor de umidade utilizado. A plataforma deste estudo (Figura 1) foi desenvolvida com dimensões específicas para calibração de uma sonda de capacitância, em laboratório, modelo Sentry 200-AP (Troxler Laboratories, Inc., Research Triangle Park, NC,
USA) semelhante à descrita por Dean et al. (1987). Este mesmo design de plataforma e sistema de pesagem também pode ser utilizado para calibração de sondas de capacitância multisensores, a exemplo do modelo EnviroScan (EnviroSCAN, Sentek Pty Ltd., South Austrália, Austrália). Características deste modelo multisensor de sonda foram apresentadas por Paltineanu \& Starr (1997). As sondas de capacitância requerem a instalação de tubos de acesso do sensor de umidade, de forma a evitar seu contato direto com o solo. Semelhantes cuidados são igualmente exigidos por sondas de nêutrons.

Segundo Gonçalves Júnior (2004), calibração é um procedimento experimental através do qual são estabelecidas, sob condições específicas, as relações entre os valores indicados por um sistema de medição e os valores correspondentes às grandezas estabelecidas por padrões. A calibração do sistema de pesagem aqui descrito foi realizada seguindo recomendações de Wheeler \& Gangi (1996). Para tanto, utilizaram-se massas-padrão de fabricação da Toledo do Brasil S.A., rastreadas à Rede Brasileira de Calibração e atendendo aos requisitos das Normas ISO 9000. Como a capacidade máxima da célula de carga era de $60 \mathrm{~kg}$, a carga máxima aplicada foi de $59 \mathrm{~kg}$. Este cuidado objetivou evitar sobrecarga na célula tendo em vista o peso adicional da plataforma.

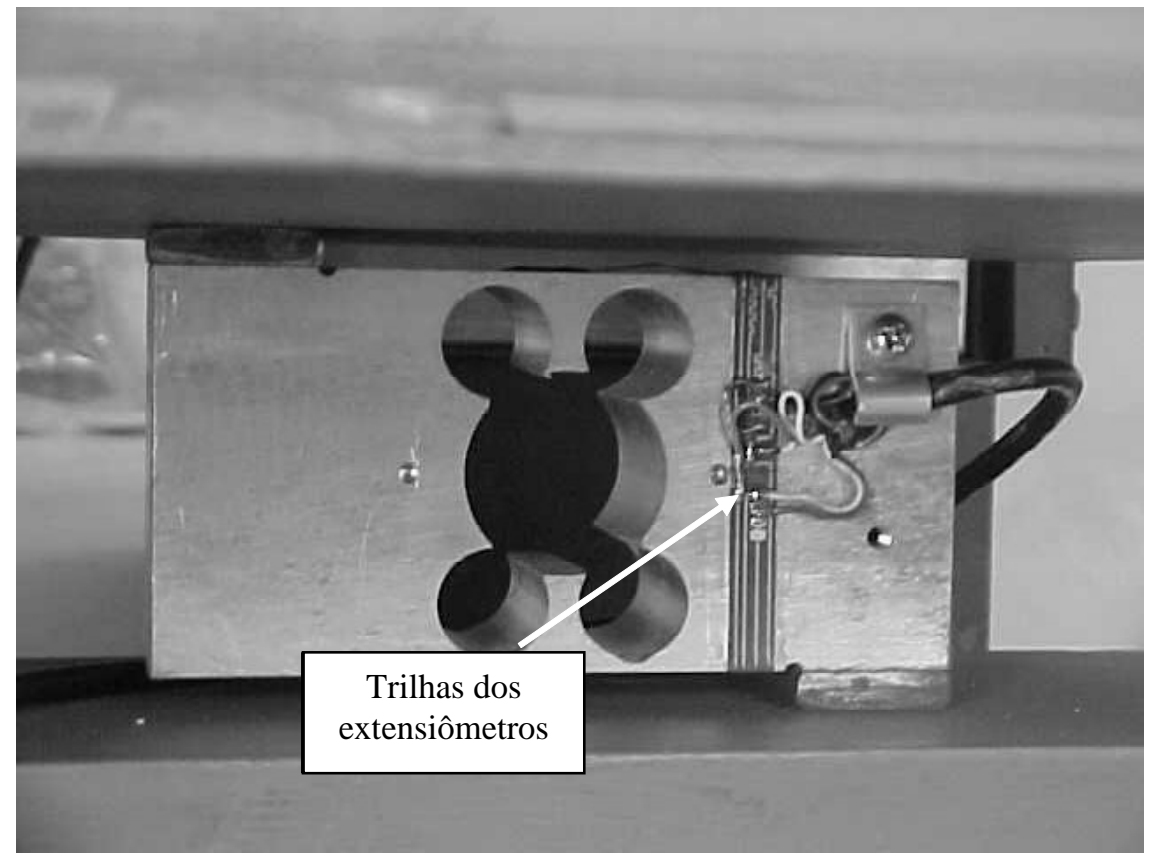

FIGURA 2 - Detalhe da célula de carga do tipo flexão.

Ciênc. agrotec., Lavras, v. 30, n. 6, p. 1162-1169, nov./dez., 2006 
De acordo com o procedimento sugerido por Wheeler \& Gangi (1996), massas-padrão foram gradativamente adicionadas e retiradas da plataforma de pesagem, em vários ciclos de carregamento e descarregamento. Sete ciclos foram realizados, anotandose as massas aplicadas e os correspondentes valores lidos no módulo indicador. Entre valores aplicados e medidos, o conjunto de dados obtidos totalizou 252 pares ordenados. De posse dessas informações os seguintes parâmetros de performance do sistema de pesagem foram determinados: erro de repetibilidade, erro de histerese, erro de linearidade e acurácia.

Os erros de repetibilidade e histerese são de precisão, por não se repetirem a cada leitura, não podendo, portanto, ser compensados (COELHO FILHO et al., 2004). O erro de repetibilidade correspondeu à máxima diferença entre as medidas seguindo uma única direção, carregamento ou descarregamento, considerando todos os ciclos e o erro de histerese correspondeu à máxima diferença entre as leituras quando efetuadas de forma crescente (carregamento) ou decrescente (descarregamento) em todos os ciclos de calibração (WHEELER \& GANGI, 1996).

O erro de linearidade é um erro sistemático que exprime o quanto a resposta de um sistema afasta-se de uma reta (GONÇALVES JÚNIOR, 2004). Inicialmente, os desvios médios foram plotados em função da massa aplicada e uma reta de referência foi obtida unindo-se os pontos máximo e mínimo do intervalo dos desvios. A maior distância dos pontos em relação à reta foi tomada como sendo o erro de linearidade (WHEELER \& GANGI, 1996).

A acurácia ou erro máximo de um instrumento é o parâmetro que melhor define a sua qualidade, pois inclui os efeitos dos erros sistemáticos e de precisão (aleatórios) nas medições (GONÇALVES JÚNIOR, 2004). Os limites de acurácia foram expressos em termos do maior e menor desvio entre todos os ciclos de carregamento e descarregamento do processo de calibração (WHEELER \& GANGI, 1996).

\section{RESULTADOS E DISCUSSÃO}

Na Tabela 1, apresentam-se os dados de calibração do sistema de pesagem para os sete ciclos de carregamento e descarregamento, com os desvios já calculados como a diferença entre a massa aplicada e a leitura do módulo indicador. $\mathrm{O}$ erro de repetibilidade do sistema de pesagem foi de $70 \mathrm{~g}$.
Para uma dada massa aplicada obteve-se a diferença entre os valores indicados pelo módulo durante a etapa de carregamento e de descarregamento. Com estas diferenças construiu-se a Tabela 2 com o objetivo de se determinar o erro de histerese do sistema de pesagem, cujo valor encontrado foi de $40 \mathrm{~g}$, correspondente à aplicação de uma massa de $20000 \mathrm{~g}$.

A curva de calibração do sistema de pesagem é mostrada na Figura 3. O coeficiente angular da equação de calibração foi igual a 1 , sendo considerado o valor ideal por se tratar de um sistema de indicação direta. No caso do coeficiente linear o valor obtido de 2,367 é superior a zero, considerado o ideal, porém é inferior à resolução do módulo indicador $(10 \mathrm{~g})$. A equação de calibração obtida já era esperada e está de acordo com Gonçalves Júnior (2004) segundo o qual a equação que expressa a relação entre o estímulo (grandeza de entrada) e a sua resposta (saída) é linear e constituída de uma constante multiplicativa e/ou aditiva.

Os desvios médios das leituras durante as fases de carregamento e descarregamento da plataforma, juntamente com as médias dos desvios para ambas as fases combinadas são mostrados na Figura 4, que indica graficamente o valor do erro de linearidade obtido $(5,14 \mathrm{~g})$.

Para a acurácia do sistema de pesagem os limites encontrados foram $\pm 50 \mathrm{~g}$ correspondendo aos desvios extremos entre a massa aplicada na plataforma e a indicação do módulo, para todos os ciclos de carregamento e descarregamento.

Pela Tabela 3, resumem-se os parâmetros de performance resultantes da calibração do sistema de pesagem, na qual a resolução é incluída para fins de comparação. Além das unidades de massa e porcentagem do final de escala, os valores são também apresentados em termos de umidade volumétrica, neste caso para uma amostra arbitrária de solo (monólito) com as dimensões de $30 \mathrm{~cm}$ de diâmetro e $25 \mathrm{~cm}$ de altura. Amostras desse tamanho são requeridas para calibração de sensores de capacitância em condições de laboratório (Figura 5), devido à inserção do tubo de acesso do sensor e do volume de solo medido no campo em condições reais de funcionamento. A umidade do solo fornecida pela sonda Sentry 200-AP, por exemplo, corresponde à umidade média num volume de solo de $20 \mathrm{~cm}$ de diâmetro por 10 cm de altura (LEY et al., 1992). 
TABELA 1 - Desvios e erros de repetibilidade por ciclo durante o processo de calibração do sistema de pesagem.

\begin{tabular}{|c|c|c|c|c|c|c|c|c|}
\hline \multirow{2}{*}{$\begin{array}{c}\text { Massa } \\
\text { aplicada } \\
(\mathrm{g}) \\
\end{array}$} & \multicolumn{7}{|c|}{ Desvios (g) } & \multirow{2}{*}{$\begin{array}{c}\text { Erros de } \\
\text { repetibilidade } \\
(\mathrm{g}) \\
\end{array}$} \\
\hline & Ciclo 1 & Ciclo 2 & Ciclo 3 & Ciclo 4 & Ciclo 5 & Ciclo 6 & Ciclo 7 & \\
\hline 10000 & 0 & 0 & 0 & 0 & 0 & 0 & 0 & 0 \\
\hline 20000 & 0 & -10 & -10 & -10 & -10 & 0 & 0 & 10 \\
\hline 30000 & 30 & 0 & 0 & -10 & -20 & 0 & 10 & 50 \\
\hline 40000 & 0 & -10 & -10 & -20 & -20 & 0 & 10 & 30 \\
\hline 42000 & 0 & -10 & -10 & -20 & -20 & 0 & 10 & 30 \\
\hline 44000 & 10 & -10 & -20 & -20 & -20 & 0 & 10 & 30 \\
\hline 46000 & 10 & -10 & -20 & -20 & -20 & 0 & 10 & 30 \\
\hline 48000 & 10 & -10 & -20 & -20 & -20 & 0 & 10 & 30 \\
\hline 50000 & 20 & -10 & -20 & -20 & -20 & 0 & 10 & 40 \\
\hline 51000 & 20 & -10 & -20 & -20 & -20 & 10 & 10 & 40 \\
\hline 52000 & 20 & -10 & -20 & -20 & -20 & 0 & 20 & 40 \\
\hline 53000 & 20 & -10 & -20 & -10 & -20 & 0 & 20 & 40 \\
\hline 54000 & 20 & -10 & -20 & -20 & -20 & 0 & 20 & 40 \\
\hline 55000 & 20 & -10 & -20 & -10 & -10 & 0 & 20 & 40 \\
\hline 56000 & 20 & -10 & -20 & -10 & -10 & 10 & 20 & 40 \\
\hline 57000 & 20 & -10 & -30 & -20 & -10 & 10 & 20 & 50 \\
\hline 58000 & 20 & -10 & -30 & -20 & -10 & 10 & 20 & 50 \\
\hline 59000 & 20 & -20 & -30 & -20 & -10 & 10 & 20 & 50 \\
\hline 58000 & 20 & -20 & -30 & -20 & 0 & 0 & 20 & 50 \\
\hline 57000 & 20 & -20 & -30 & -20 & 0 & 0 & 20 & 50 \\
\hline 56000 & 20 & -20 & -30 & -20 & 0 & 0 & 20 & 50 \\
\hline 55000 & 20 & -20 & -30 & -20 & 0 & 0 & 20 & 50 \\
\hline 54000 & 20 & -20 & -30 & -20 & 0 & 10 & 20 & 50 \\
\hline 53000 & 20 & -20 & -30 & -20 & 0 & 10 & 20 & 50 \\
\hline 52000 & 20 & -20 & -30 & -20 & 0 & 10 & 20 & 50 \\
\hline 51000 & 20 & -20 & -40 & -30 & 0 & 10 & 20 & 60 \\
\hline 50000 & 20 & -20 & -40 & -30 & 0 & 0 & 10 & 60 \\
\hline 48000 & 20 & -30 & -50 & -20 & -20 & 20 & 20 & 70 \\
\hline 46000 & 20 & -30 & -40 & -30 & -20 & 20 & 20 & 60 \\
\hline 44000 & 20 & -20 & -50 & -20 & -20 & 20 & 20 & 70 \\
\hline 42000 & 20 & -30 & -50 & -20 & -20 & 20 & 20 & 70 \\
\hline 40000 & 20 & -30 & -50 & -30 & -20 & 20 & 20 & 70 \\
\hline 30000 & 30 & -20 & -40 & -20 & -10 & 10 & 20 & 70 \\
\hline 20000 & 40 & -10 & -30 & -30 & 0 & 10 & 30 & 70 \\
\hline 10000 & 30 & -20 & -30 & -20 & 0 & 0 & 20 & 60 \\
\hline 0 & 30 & -20 & -30 & -20 & 0 & 0 & 20 & 60 \\
\hline
\end{tabular}

Ciênc. agrotec., Lavras, v. 30, n. 6, p. 1162-1169, nov./dez., 2006 
TABELA 2 - Desvios para obtenção do erro de histerese.

\begin{tabular}{cccccccc}
\hline \multirow{2}{*}{ Massa aplicada (g) } & \multicolumn{7}{c}{ Desvios $(\mathbf{g})$} \\
\cline { 2 - 8 } & Ciclo 1 & Ciclo 2 & Ciclo 3 & Ciclo 4 & Ciclo 5 & Ciclo 6 & Ciclo 7 \\
\hline 10000 & 30 & -20 & -30 & -20 & 0 & 0 & 20 \\
20000 & 40 & 0 & -20 & -20 & 10 & 10 & 30 \\
30000 & 0 & -20 & -40 & -10 & 10 & 10 & 10 \\
40000 & 20 & -20 & -40 & -10 & 0 & 20 & 10 \\
42000 & 20 & -20 & -40 & 0 & 0 & 20 & 10 \\
44000 & 10 & -10 & -30 & 0 & 0 & 20 & 10 \\
46000 & 10 & -20 & -20 & -10 & 0 & 20 & 10 \\
48000 & 10 & -20 & -30 & 0 & 0 & 20 & 10 \\
50000 & 0 & -10 & -20 & -10 & 20 & 0 & 0 \\
51000 & 0 & -10 & -20 & -10 & 20 & 0 & 10 \\
52000 & 0 & -10 & -10 & 0 & 20 & 10 & 0 \\
53000 & 0 & -10 & -10 & -10 & 20 & 10 & 0 \\
54000 & 0 & -10 & -10 & 0 & 20 & 10 & 0 \\
55000 & 0 & -10 & -10 & -10 & 10 & 0 & 0 \\
56000 & 0 & -10 & -10 & -10 & 10 & -10 & 0 \\
57000 & 0 & -10 & 0 & 0 & 10 & -10 & 0 \\
58000 & 0 & -10 & 0 & 0 & 10 & -10 & 0 \\
\hline
\end{tabular}

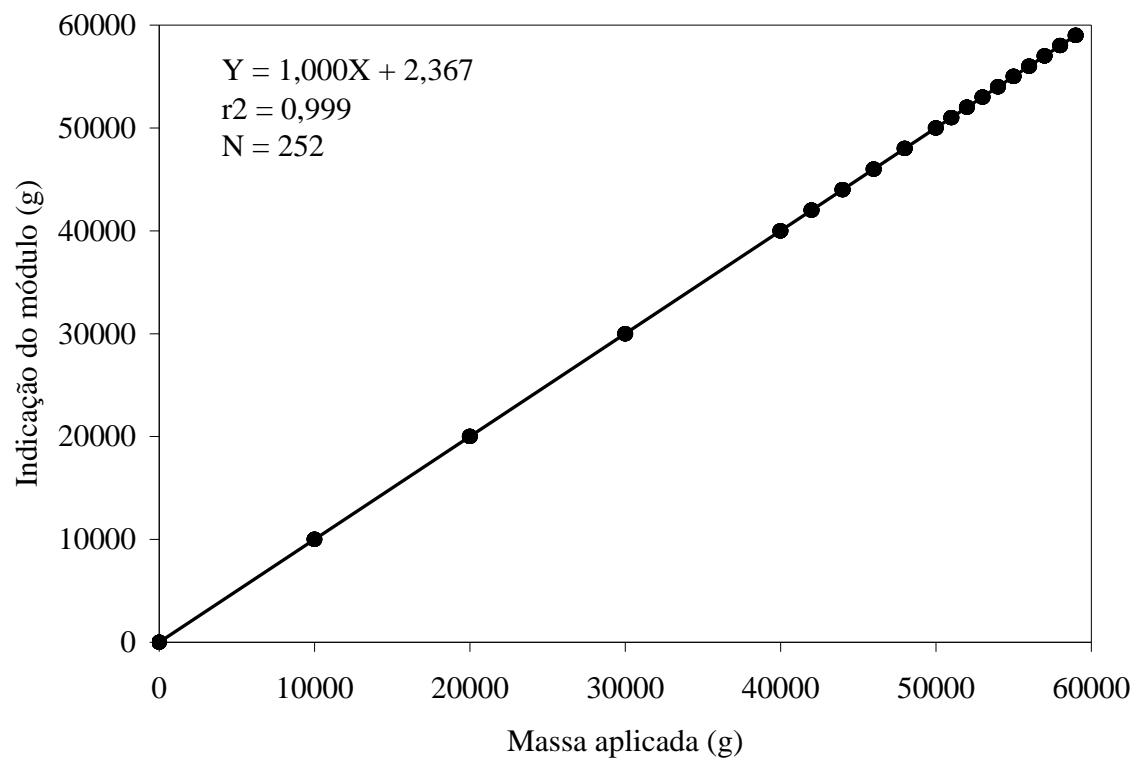

FIGURA 3 - Curva de calibração do sistema de pesagem. 
Os valores encontrados para os erros de repetibilidade, histerese, linearidade e acurácia estão dentro de uma faixa aceitável já que expressos em termos de umidade volumétrica representaram $0,396 \%, 0,226 \%$, $0,029 \%, \pm 0,283 \%$, respectivamente, considerando uma amostra de solo cilíndrica de $30 \mathrm{~cm}$ de diâmetro e $25 \mathrm{~cm}$ de altura. Do conjunto de erros avaliados a repetibilidade foi o que mais contribuiu para a acurácia do sistema de pesagem, principal erro indicador da performance de um instrumento de medição. Isto implica em que o erro de acurácia do sistema foi em geral influenciado por fatores que não podem ser controlados pelo experimentador.

O custo final de montagem do sistema de pesagem é estimado em $\mathrm{R} \$ 1.820,00$, assim distribuídos: $\mathrm{R} \$ 300,00$ (célula de carga), $\mathrm{R} \$ 1.500,00$ (módulo indicador digital), $\mathrm{R} \$ 20,00$ (chapa de aço de $0,16 \mathrm{~m}^{2}$ ).

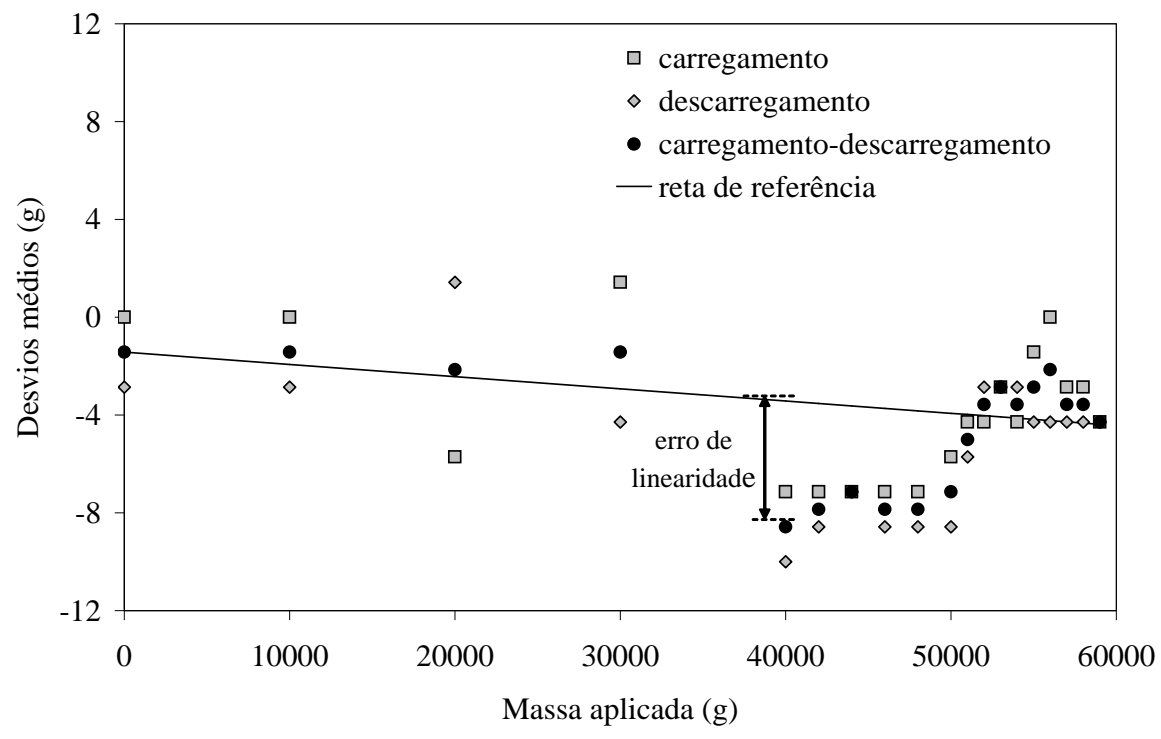

FIGURA 4 - Plotagem dos desvios médios em função da massa aplicada, com indicação gráfica do erro de linearidade.

TABELA 3 - Características técnicas do sistema de pesagem.

\begin{tabular}{lccc}
\hline \multirow{2}{*}{ Parâmetro de Performance } & \multicolumn{3}{c}{ Valor } \\
\cline { 2 - 4 } & $\begin{array}{c}\text { Massa } \\
(\mathbf{g})\end{array}$ & $\begin{array}{c}\text { Percentual } \\
(\mathbf{\%} \mathbf{~ F E}) *\end{array}$ & $\begin{array}{c}\text { Umidade volumétrica } \\
(\boldsymbol{\%}) * *\end{array}$ \\
\hline Erro de repetibilidade & 70,00 & 0,1186 & 0,396 \\
Erro de histerese & 40,00 & 0,0678 & 0,226 \\
Erro de linearidade & 5,14 & 0,0087 & 0,029 \\
Acurácia & $\pm 50,00$ & $\pm 0,0833$ & $\pm 0,283$ \\
Resolução & 10,00 & 0,0170 & 0,057 \\
\hline
\end{tabular}

*Final de escala.

**Para uma amostra de solo cilíndrica de $30 \mathrm{~cm}$ de diâmetro e $25 \mathrm{~cm}$ de altura.

Ciênc. agrotec., Lavras, v. 30, n. 6, p. 1162-1169, nov./dez., 2006 


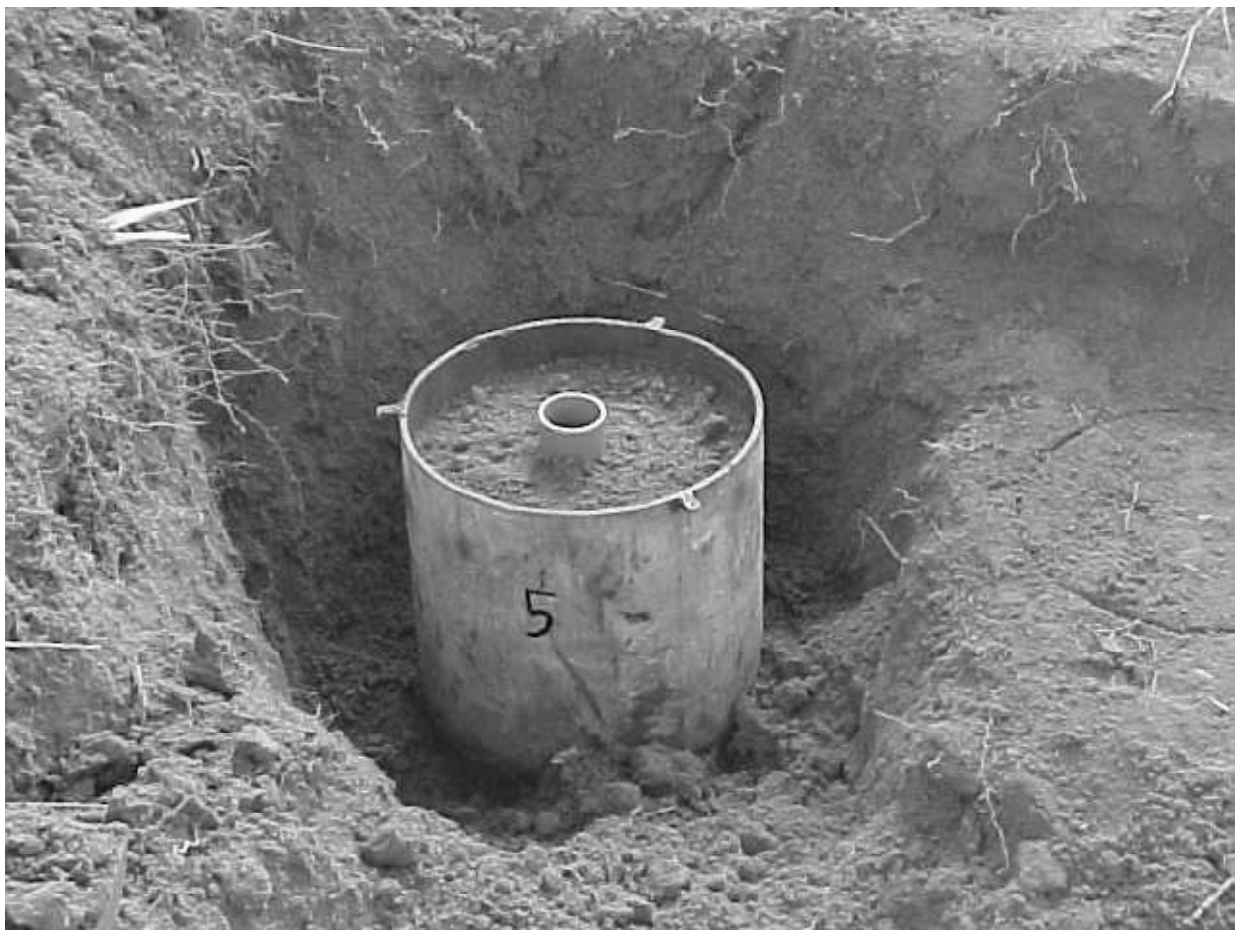

FIGURA 5 - Exemplo de monólito para calibração de sonda de capacitância.

\section{CONCLUSÕES}

O sistema de pesagem proposto revelou-se funcional, prático e de baixo custo e adequado, com base nos parâmetros de desempenho, para utilização em processos de calibração de sensores de umidade do solo. A acurácia global do sistema de pesagem da ordem de $\pm 50 \mathrm{~g}$ é aceitável quando se necessita pesar massas de solo de grande volume, a exemplo das requeridas para calibração de sondas de capacitância.

\section{REFERÊNCIAS BIBLIOGRÁFICAS}

COELHO FILHO, M. A.; VELLAME, L. M.; COELHO, E. F.; SOUZA, C. F. Instalação e operação de sistemas de aquisição e armazenamento de dados para o monitoramento do sistema solo-planta-atmosfera. Cruz das Almas: Embrapa/CNPMF, 2004. 136 p. (Documentos, 143).

DEAN, T. J.; BELL, J. P.; BATY, A. J. B. Soil moisture measurement by an improved capacitance technique: part I: sensor design and performance. Journal of Hydrology, Amsterdam, v. 93, p. 67-68, 1987.

GILBERTO JÚNIOR, O. J. Desempenho do reflectômetro no domínio do tempo na detecção de variações de umidade do solo. 2003. 94 f. Dissertação (Mestrado) - Escola Superior de Agricultura de Luiz de Queiroz, Piracicaba, 2003.

GONÇALVES JÚNIOR, A. A. Metrologia: parte I. Florianópolis: UFSC, 2004. 129 p. Apostila.

GROENEVELT, P. H.; BOLT, G. H. Water retention in soil. Soil Science, New York, v. 113, n. 4, p. 238-245, 1971.

LEY, T. W.; STEVENS, R. G.; TOPIELEC, R. R.; NEIBBLING, W. H. Soil water monitoring and measurement. Prosser: Washington State University, 1992. 27 p.

LIBARDI, P. L. Dinâmica da água no solo. 2. ed. Piracicaba: [s.n.], 2000. 509 p.

PALTINEANU, I. C.; STARR, J. L. Real-time soil water dynamics using multisensor capacitance probes: laboratory calibration. Soil Science Society American Journal, Madison, v. 61, p. 1576-1585, Nov./Dec. 1997.

WHEELER, A. J.; GANJI, A. R. Introduction to engineering experimentation. New Jersey: Prentice Hall, 1996. 415 p. 